\title{
The Canadian Journal of Gastroenterology 2005: The new team
}

\author{
Paul Adams MD \\ Editor-in-Chief
}

I $\mathrm{t}$ is with great pleasure that I accept the position of the new Editor-in-Chief of The Canadian Journal of Gastroenterology (CJG). As the fourth Editor-in-Chief, I am building on a strong foundation which has been established by Drs Alan Thomson, Noel Williams and Lloyd Sutherland.

CJG continues to grow and is attracting a wide range of manuscripts from Canada and abroad. It is the official journal of the Canadian Association of Gastroenterology and the Canadian Association of the Study of the Liver, and I see our members as our primary audience. Many medical journals have been accused of becoming so increasingly esoteric that they have alienated their readership. An example would be Gastroenterology, where a growing swell of criticism prompted the introduction of a new journal, Clinical Gastroenterology and Hepatology, to reach their clinical membership. It comes as no surprise that the most highly cited issue of Gastroenterology is their annual issue, which includes only review articles.

The new leadership of CJG plans to re-emphasize clinical gastroenterology, hepatology and research, and a team of national leaders has been assembled. Steve Vanner is the new Senior Associate Editor and he brings to CJG a wealth of experience in GI research (basic and clinical). Rob Enns will introduce a new regular feature on GI endoscopy, which is an important topic to our members. Marc Bilodeau brings to the Journal his expertise in basic liver disease research. We have a strong group of Associate Editors based in London that includes Brian Feagan, Jack McDonald, Jamie Gregor and Paul Marotta, who bring their expertise in clinical trials, inflammatory bowel disease, liver diseases and liver transplantation. Mark Speechley is an epidemiologist who will act as an advisor to the Journal on methodology and biostatistics.
We cannot expect our members to always send their scientific work to CJG. Many articles are more specialized and appropriate to a more international journal. Our greatest asset is the collective intellect of our members and there are many articles with a distinct Canadian focus that are ideally suited to our Journal. While we welcome international submissions, we will continue to maintain our high standards and will only accept

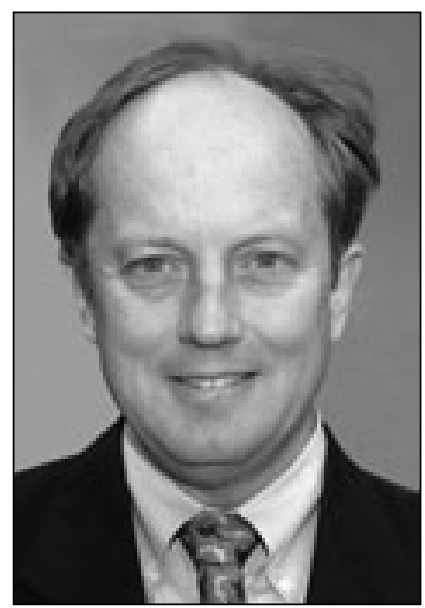

Paul Adams for consideration articles that are appropriate to CJG. We plan to focus submissions on human research in the next era of the CJG. Many of you will be asked to submit to the CJG in the next five years, and I would hope that you would view this as an honour and a privilege. We don't know about all of the special contributions of our members and I welcome community gastroenterologists to contact me about potential contributions to the Journal.

The new editorial team is brimming with new ideas and enthusiasm but, ultimately, the success of the Journal depends on the support of the Canadian Association of Gastroenterology and Canadian Association of the Study of the Liver members by the submission of new manuscripts. I look forward to your contributions. 


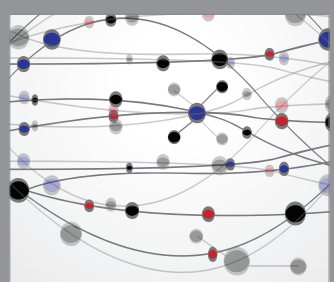

The Scientific World Journal
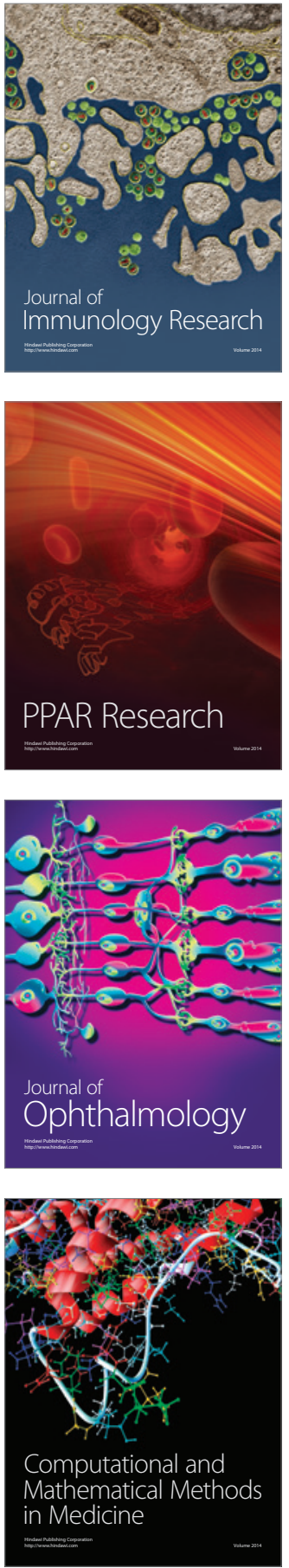

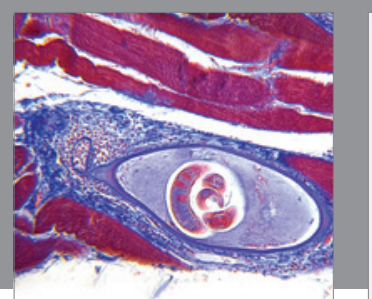

Gastroenterology Research and Practice



\section{Hindawi}

Submit your manuscripts at

http://www.hindawi.com
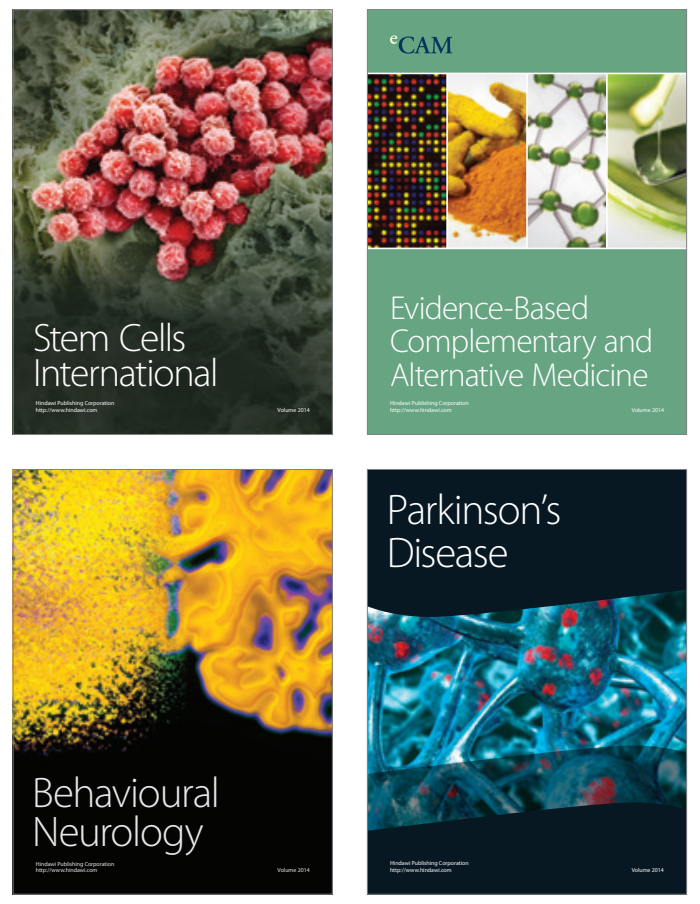
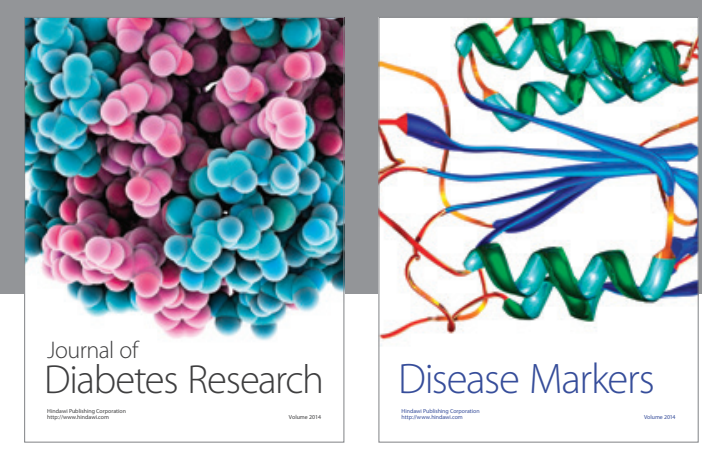

Disease Markers
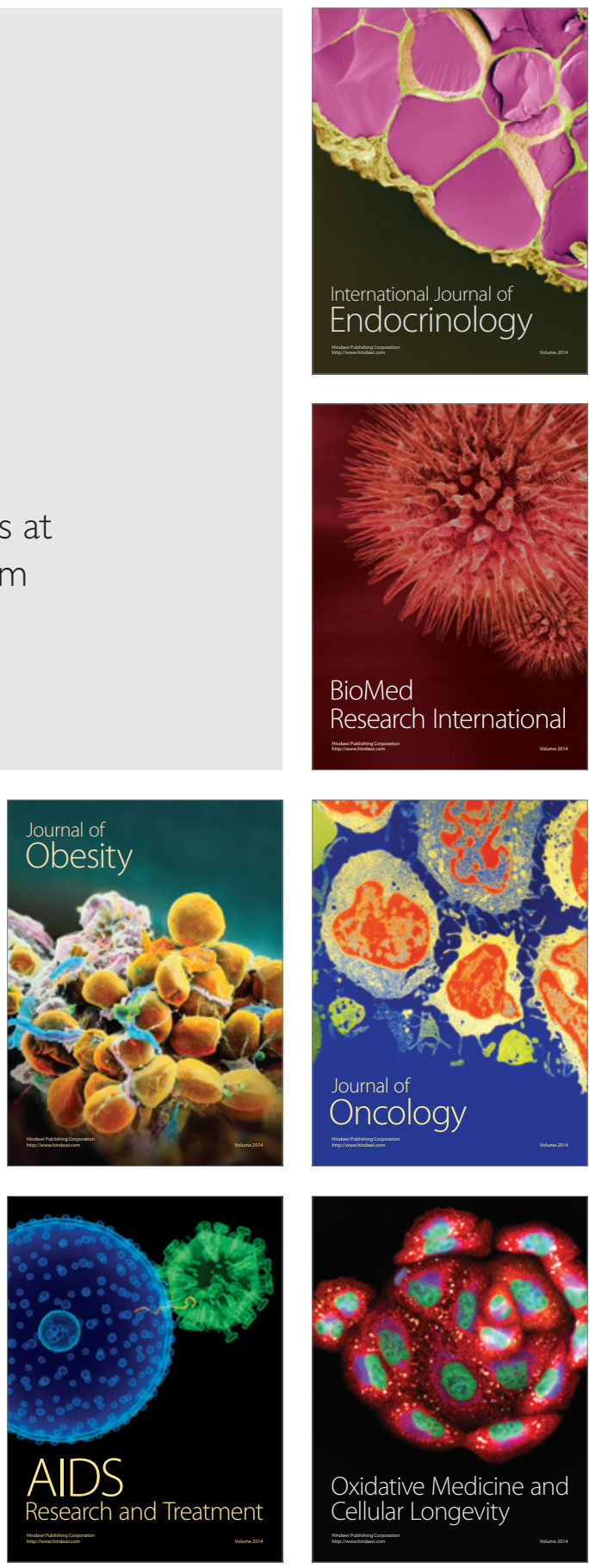